\title{
A Commentary on "A Health Education Perspective on Sexual Risk Taking Behavior in Perimenopausal Women"
}

\author{
Ansa Ojanlatva \\ University of Turku/Finland
}

\begin{abstract}
This is a commentary on, "A Health Education Perspective on Sexual Risk Taking Behavior in Perimenopausal Women" by Silvea Thomas, California Journal of Health Promotion 2004, 2(1), 56-60.
\end{abstract}

(C) 2004 Californian Journal of Health Promotion. All rights reserved.

Keywords: commentary, perimenopausal, women's health, sexuality

It was good to see an article on a (sexual) health promotion issue of women aged 45-55 years for a change. And I appreciate the opportunity to make comments to further explain the issues.

\section{Terms}

Perimenopause (perimenopausal) points to a biological finding that the ovaries are changing in their function. This phase of the ending menstruation is estimated to be a 2-to-8-year time period (Greendale et al., 1999). Late perimenopausal is used to describe women who have had amenorrhea for 3 months but less than 12 months, whereas postmenopausal is used to identify women who have had amenorrhea for 12 months (Dennerstein et al., 2001). Biology rather than pure clinical medicine seems to be involved here. Bastian et al. (2003) advocated the use of a woman's own menstrual history because no test is available or no one symptom is adequate in describing the outcome. For a given woman, the menopausal experience may be physiological but is likely to be genetically timed (Rymer \& Morris, 2000).

I am thus a little puzzled as to why the adjective (perimenopausal) was used to describe 45-55-year-old women. When a medical term is assumed and used, it tends to lead to medicalization, which has slowly happened in women's lives. In order to avoid this, an illustration of the age group itself would have been adequate in the abstract. This period of a woman's life (45-55 years of age) is now referred to as the climacterium (Topo \& Hemminki, 1995).

Second, Dr. Thomas did not list sexual in the first sentence when describing the metamorphosis. "Sexual" just popped up as a space filler, and I got an odd feeling that the sexuality issue was not really soughtafter within this article. Yet, a true sexual aspect is involved during the climacterium and likely to be specifically recognized as part of the genuine perimenopausal changes. In a recent study of 42-46 and 5256-year-old women responding to a question about reasons for the lack of sexual desire, the younger group perceived hormones as the most common reason from the alternatives (Jokinen et al., 2003). In the background study of the two groups of women and their sexuality, lack of sexual desire was more commonly perceived among those with a spouse/partner than among those without one, with an interpretation that those without one could more clearly make a determination about sexual interaction (Ojanlatva et al., 2004).

Third, risk taking will need further clarification as a term. Some years back, Prof. Stina Syrjänen mentioned to me that women in their 40s were at risk for contracting HPV. Following separation/ 
divorce, these women were new at the dating game, or re-established, as the wording may be. They had used oral contraceptives as their means of contraception and did not carry condoms when they were in their stable relationship with the former spouses. It may not be politically correct to talk about marriage/marriage-like relationship not necessarily being monogamous. Nevertheless, an assumption that sex will only take place within a monogamous relationship can be a figment of one's own imagination. Women may be at risk when a third person comes into the relationship in an intimate way.

Consequently, these women may be at risk but are they risk takers? Sex and sexuality are considered normal parts of life and personality. Having sex helps to satisfy a need, whereas sexuality defines the rest of it. The fact that these women do not carry condoms does not necessarily define them as risk takers -even when they meet new people and have their own sexual needs satisfied. Sexual intercourse is known to be only one option. I would rather pose the following thought that there is a split or divide in the rites of passage. This cultural or ritual divide (not risk taking) will signify a difference from a former setting what ever it may have been. An older woman normally knows what pleases her and continues to behave the way she normally does. It is unlikely that her way of having sex was considered risk behavior with the former spouse/partner. A partner may be the only difference.

\section{Sexually Transmitted Infections}

As far as women are concerned, the age group of 45-55 years old is present in the reportable infection statistics of this country (http://www.ktl.fi). Many of the over 20 infections known to be sexually transmitted are not reported, however. From the rates and other information, it looks as if there are years of reporting when the rates change for both men and women rather than it being obvious that the older age groups would have less reporting. If the reporting is becoming less reliable in general then we have a serious problem.

\section{Research and Women's Sexuality}

Women's lives are connected with reproduction, as readers may have detected from the article as well. It is difficult to receive funding for research on women and sexuality. Funding agencies do respond to inquiries about non-funded applications, but explanations are not always believable.

For years now, I have been sending in applications on women's health and sexuality to one of three national offices that jointly grant health promotion monies for research in this country. There does not seem to be any objection to work on the issue but the time and endeavor are accepted as donations to science rather than providing pay and other rewards for the efforts. And nobody seems to have an inkling as to how these issues could be synchronized.

In response to the latest inquiry about the outcome of the review, I got a short note saying that there was nothing wrong with the proposal. They just had to draw the line somewhere. The proposal was "too narrow as far as the national interests" were concerned. Did it mean the age groups (42-46- and 52-56year-olds), the topics (sexuality and health), or the gender (women)?

International statistics at the time of the application indicated that women 75 years of age or over would be the age group increasing in size the most in less than 50 years. The age group alone would contribute to it being of national interest, I thought. These women will spend a large part of the medical resources unless they stay reasonably healthy and fulfilled until their death.

I reminded them that Health 2015 mentions perceived health, an improvement of human relations, and a reduction of violence. Our finding indicated that a good relationship with one's own mother is essential for importance and satisfaction of sex life in adulthood and that it would be better to have no mother at all than to have a poor relationship with one (Ojanlatva et al., 2003a). More Finnish women than men are satisfied with and find it easier to talk about sex life with an important other (Ojanlatva et al., 2003b). 
Copies were enclosed with the application. The response was that we are probably not going to be able to come to an agreement on this.

Then I realized that the "narrow national interest" must be about the combination of middle-aged women and sexuality, just as Dr. Thomas indicated. It is not so much that there would not be interest to research. It just does not get funded, probably in part because the monies are allocated by reasonably young male staff members who do not see beyond the women's years of reproduction or appreciate women's health and sexuality as topics to be investigated. I guess this will be an example of those situations when gender specific data from men will applied to women of the same age.

\title{
References
}

Bastian, L. A., Smith, C. M., \& Nanda, K. (2003). Is this woman perimenopausal? Journal of the American Medical Association, 289, 895-902.

Dennerstein, L., Dudley, E., \& Burger, H. (2001). Are changes in sexual functioning during midlife due to aging or menopause? Fertility and Sterility, 76, 456-460.

Greendale, G. A., Lee, N. P., \& Arriola, E. R. (1999). The menopause. The Lancet, 353, 571-580.

Jokinen, K., Rautava, P., Mäkinen, J., Ojanlatva et al. (2003). Experience of climacteric symptoms among 42-46 and 52-56- year old women. Maturitas, 46, 199-205.

Ojanlatva, A., Helenius, H., Rautava, P., Ahvenainen, J., \& Koskenvuo, M. (2003b). Importance of and satisfaction with sex life in a large Finnish population. Sex Roles, 48, 543-553.

Ojanlatva, A., Helenius, H., Rautava, P., Ahvenainen, J., Koskenvuo, M. (2003a). Will childhood relationships with parents contribute to a satisfying sex life? Sexual and Relationship Therapy, 18:204-214.

Ojanlatva, A., Helenius, H., Jokinen, K., Sundell, J., Mäkinen, J., Rautava, P. (2004). Sexual activity and background variables among women of 42-46 and 52-56 years. American Journal of Health Behavior, 28 (Suppl.), 302-315.

Rymer, J., \& Morris, E. P. (2000). Extracts from "clinical evidence": menopausal symptoms. British Medical Journal, 321, 1516-1519.

Topo, P., \& Hemminki, E. (1995). Is menopause withering away? Journal of Biosocial Science, 27, 26776.

\author{
Author Information \\ Ansa Ojanlatva, PhD, CHES, CSE \\ Dept. of Teacher Education, and Institute of Biomedicine \\ Center for Reproductive and Development \\ Sanitas 3rd floor, Lemminkäisenkatu 1 \\ 20014 University of Turku/Finland \\ Ph. 358-2-333 8513 \\ Fax. 358-2-333 8439 \\ E-Mail: ansa.ojanlatva@utu.fi
}

